\title{
A sustainable museum collection of historical imagery for coral reef baselines
}
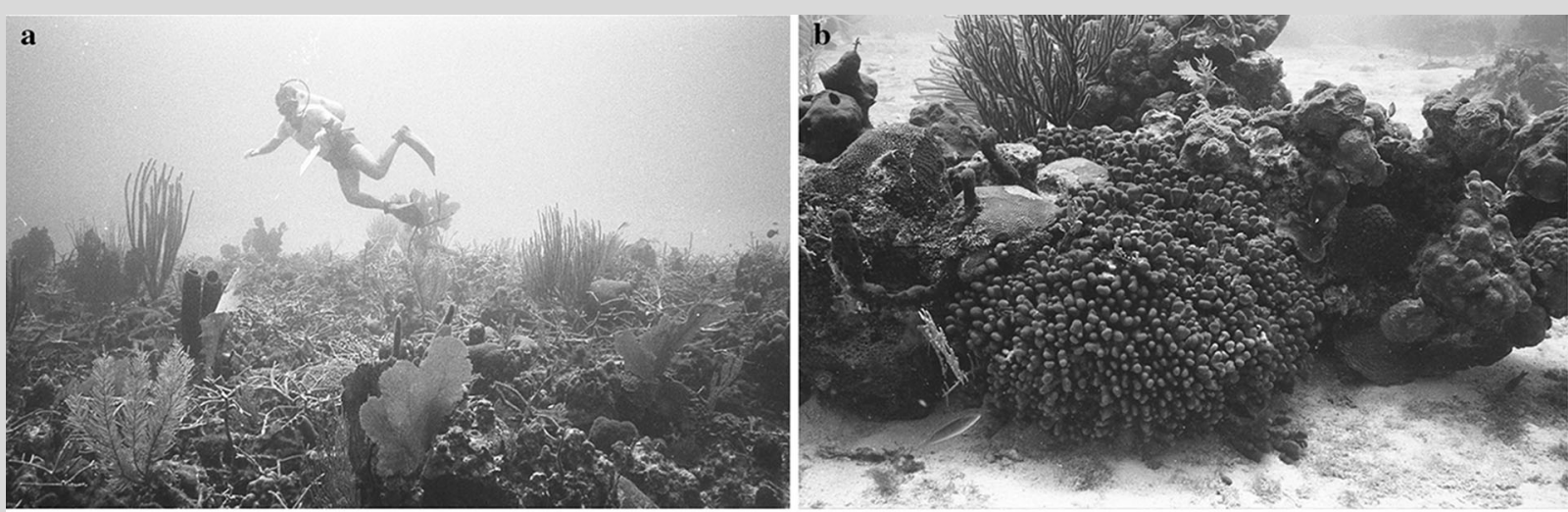

c

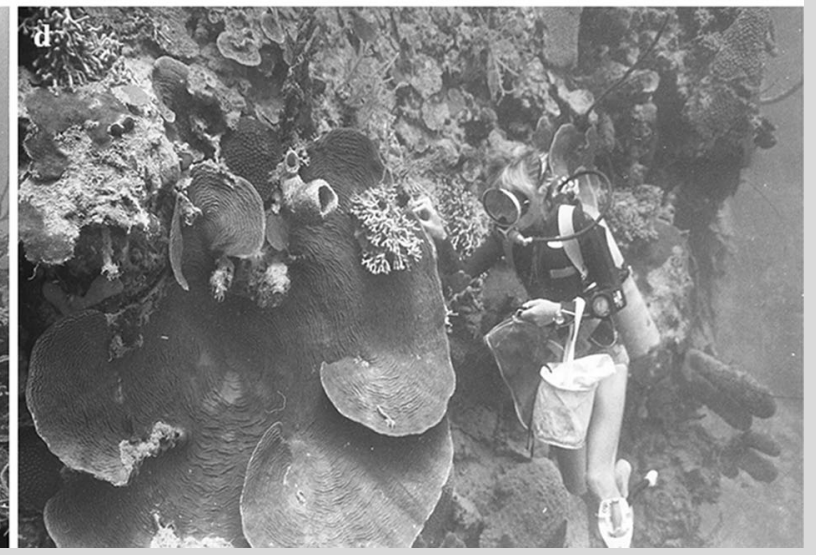

Fig. 1 Images of Discovery Bay from the archive made by Eileen Graham. a Spur reef on fore-reef terrace, Upper Buoy Reef area, 21 m, August 1966 . b Outcrop in sand channel on fore-reef slope, Upper Buoy Reef, $\sim 17$ m, September 1967. c Pinnacle One fore-reef slope reef, $\sim 23$ m, October 1966 . d Eaton Hall First Groyne, vertical fore-reef escarpment, 24 m, June 1966

Understanding ecological shifts documented on coral reefs over recent decades (Hoegh-Guldberg 2014) requires reconstruction of historical baselines. Underwater photographs of known reef sites are especially valuable sources of historical data (Fig. 1). As part of a new initiative to create a sustainable, open-access repository of historical reef imagery and associated data, a collection of over one thousand images made by Eileen Graham in the mid-1960s near Discovery Bay Jamaica is available for download (Johnson et al. 2016). They record the condition of reefs prior to their decline in the 1980s and before well-establishec monitoring surveys in the Caribbean. Images range from detailed close-ups to reefscapes and are a potentially rich source of ecological data including benthic community composition, habitat complexity, and disease presence. Ecological change on coral reefs shows great variability at local scales, so site-specific data may not suffice to inform decision-makers; thus, we aim to establish a network of image repositories from reefs worldwide to help define local baselines. We encourage reef scientists, underwater photographers, and recreational divers with well-organized photographic records to collaborate and share their images as part of this initiative, and urge their use for research, conservation planning, and simply as a visual reference of the changes undergone by coral reefs.

Acknowledgments We thank Eileen Graham for sharing her amazing photographs from the north coast of Jamaica from the 1960s. FC received support from the SCCS Miriam Rothschild Internship Programme for this work.

Open Access This article is distributed under the terms of the Creative Commons Attribution 4.0 International License (http://creativecommons.org/licenses/by/4.0/), which permits unrestricted use, distribution, and reproduction in any medium, provided you give appropriate credit to the original author(s) and the source, provide a link to the Creative Commons license, and indicate if changes were made.

References

Hoegh-Guldberg O (2014) Coral reefs in the Anthropocene: persistence or the end of the line? Geol Soc Spec Publ 395:167-183

Johnson KG, Cavada F, Darrell J, Hunter W, Lang J, Santodomingo N, Yarlett R (2016) Dataset: Coral reef imagery by Eileen Graham of Jamaica in the 1960s. http://dx.doi.org/10.5519/0008285

R. Yarlett

Department of Geography, University of Exeter, Exeter EX4 4RJ, UK

F. Cavada

Laboratorio de Ecología Experimental, Universidad Simón Bolívar, Caracas, Venezuela

J. Lang

AGGRA, PO Box 539, Ophelia, VA, USA

K. G. Johnson (禺)

Department of Earth Sciences, Natural History Museum, London SW7 5B, UK

e-mail: k.johnson@nhm.ac.uk

Received: 2 December 2015/Accepted: 14 February 2016/Published online: 5 March 2016

Coral Reefs (2016) 35:527

(C) The Author(s). This article is published with open access at Springerlink.com 2016

DOI $10.1007 / \mathrm{s} 00338-016-1426-\mathrm{z}$ 